\title{
Effects of Flipped Classroom based on Smart Learning on Self-directed and Collaborative Learning*
}

\author{
Sang-Hong Kim ${ }^{1}$, Nam-Hun Park $^{2}$ and Kil-Hong Joo ${ }^{3 \dagger}$ \\ ${ }^{1,3}$ Dept. of Computer Education, Gyeongin National University of Education, Korea \\ ${ }^{2}$ Dept. of Computer Science, Anyang University, Korea \\ 1'bestteacher@gmail.com, ${ }^{2}$ nmhnpark@anyang.ac.kr, ${ }^{3}$ khjoo@ginue.ac.kr
}

\begin{abstract}
This study seeks to explore the effects of smart-based flipped learning activities on learners' study achievement, self-directed learning, collaborative learning and information use ability. To achieve this study purpose, 112 6th-grade students in the elementary school $P$ in Gympo-si, Gyeonggi-do South Korea were selected as this research experiment group (Flipped classroom based on smart-learning, and normal flipped learning) as well as the control group (traditional ICT-based class learning). They were examined for 11 weeks from the 2nd week of March to 2nd week of May, 2014. In the Flipped classroom based on smartlearning, the participants studied at home in advance with materials made by their teachers. Then, in class, they searched data instantly by using smart pads, used applications for learning or as a tool, and conducted online evaluation, etc. The normal flipped learningbased education group studied at home in advance with videos made by their teachers and, in class, they were instructed to focus on knowledge sharing among themselves and discussions. As a result, an effect on study achievement was found between the flipped learning and traditional ICT-based learning methods. And the smart-based flipped learning was found to have improved self-directed learning ability more than the general flipped learning and traditional ICT-based method. Collaborative learning ability and information use ability were found to be more improved with statistical significance in the smart-based flipped learning group than the other groups.
\end{abstract}

Keywords: flipped learning, smart education, self-directed learning, collaboration ability, information use ability

\section{Introduction}

Many scholars have asked and answered about how learning is achieved. Renowned scholars of cognitivism, behaviorism and Constructivism have talked about learning. Still school education has failed to make learning be constructed by students themselves while just delivering knowledge in a unilateral manner for the most part. As smart education has been activated recently, studies have increasingly shown that change of educational media had affected learners' capacity. However, no remarkable change has seen in the way of teaching. Although the opportunities for students to use different media to directly engage in classes rose, learning is still performed via knowledge delivery by teachers (Jeongrang Kim, et al., 2014). Studies on the organization of learning stated that 'learning is the result of educational self-organization', 'learning is revealed when education process is formed by oneself',

\footnotetext{
* This paper is a revised and expanded version of a paper entitled "Analysis of Effectiveness of Flipped Classroom based on Smart Learning" presented at NGCIT2014.

$\dagger$ Corresponding Author
} 
'learning is not to be made but to be earned by oneself'. And teachers should prepare for the facilitation of the process then they need to stand back and watch the learning process going on on its own with due respect (Sugata Mitra, 2010). In the mean time, through the SOLE (Self Organizing Learning Environments) project, the results of students' self-initiated learning could be observed in normal classes through broadband communication, collaboration and encouragement.

From the perspective of Constructivism, teachers do not play a role to deliver knowledge but a role to facilitate knowledge. And they present practical tasks to students and give appropriate guidance, questions and answers to facilitate mutual interaction between learners and provoke more thoughts. That is, teachers are facilitators (Inae Gang, 2013). Instead of teacher-oriented classes, more student-oriented classes are demanded. But the current school education does not meet this demand. It is not because teachers do not know appropriate teaching methods or do not try various attempts. In the current educational regime focused solely on entering a good university, teachers are burdened to deliver more to students in this regard. Also, there are too much contents to be delivered in just one single class to try diverse teaching methods. Teachers' autonomy is not large enough to change curriculum details. As teachers take various other tasks in school, in reality, they cannot concentrate solely on classes (Min Jeong, 2014).

A flipped learning-type class can be a solution to those problems above. Normally, we cannot say learning is being made just because a teacher teaches students in a knowledge delivering manner. However, in the flipped learning-type class, students can internalize knowledge as they are to preview the basic related ideas outside the school via videos and conduct diverse in-class activities such as discussion, collaboration, quiz, project, etc. Students can change tacit knowledge into explicit knowledge through peer instruction. Tacit knowledge refers to the kind of knowledge that is not expressed in a certain form but just accumulated through experience and learning. Such knowledge can be expressed in a certain format through peer instruction among diverse interaction between students. Also, while students express in speech or writing their knowledge obtained through the video, they organize and systemize the knowledge to initiate learning.

This kind of study has yet to be much frequent in South Korea. Whereas studies on the relationship between flipped learning and classes have been active abroad. From elementary school level to high school level, studies have examined the effects of flipped learning on study achievement, the effect of individualized education and teachers' satisfaction level (Baker, Celia, 2012; Bergmann, J. \& Sams, A., 2012). In South Korea, there have been some studies on the effect or method of flipped learning at a high school level but studies at the elementary school level are far less than sufficient.

In this situation the present study, based on the foresaid theoretical background that the flipped learning-based education in elementary schools with a smart educational environment would have an effect on students' collaborative ability, self-directed learning ability and study achievement, the following research themes have been identified. This study, to explore the educational effectiveness of flipped learning, seeks to examine if there is any positive effect of Flipped classroom based on smart-learning and flipped leaning-based education on selfdirected learning ability to lead own study process and collaboration ability. More specific research themes are established as follows:

1) Is there any difference in learners' self-directed study among the Flipped classroom based on smart-learning group, normal flipped learning group, and conventional ICT-based class group? 
2) Is there any difference in students' collaboration ability among the Flipped classroom based on smart-learning group, normal flipped learning group, and conventional ICT-based class group?

\section{Theoretical Background}

\subsection{Definition and Characteristics of Flipped Learning}

Flipped learning educational models have garners increasing attention from teachers and researchers. The KERIS' Smart Education Global Trend Vol. 2013 no. 17 defined flipped learning as follows (KERIS, 2013a). Flipped learning refers to flip around the conventional ways of education in order for students to listen to their teacher-generated lectures at home and participate in learning activities in class such as discussion, quiz, project, etc., to solve their tasks. The educational method turns teachers from a knowledge messenger to facilitator and is based on the thought that students' learning takes place through their school project activities as well as discussions and debates with their colleagues, etc. With the rising personal smart device penetration in the smart education field, more smart devices are applied to teaching-learning process.

According to "A Review of Flipped Learning (2013)" issued by the Flipped Learning Network, the flipped learning is divided into 4 large pillars. First, flipped learning requires a flexible environment. In other words, teachers should accept it even though their class goes sometimes very confusing and noisy. And teachers need to establish a proper evaluation system to measure the level of understanding in a meaningful manner objectively for both students and teachers. Second, flipped learning requires changes in the learning culture. These classes seek to provide affluent opportunities for students to explore study themes deeper. By doing so, they try to transform the teacher-oriented class into student-oriented class intentionally. Knowledge is built by students themselves when they proactively participate and evaluate their own learning status in a meaningful manner. In addition, this teaching method supports students to examine deeper about a theme instead of challenging too many things, so that they can reach their potential development level in own zone of proximal development or, own level of preparation or areas (Vigotsky, 1978). Third, flipped learning demands intentional contents. Teachers should adopt diversified educational methods according to school years and themes such as proactive learning strategy, peer instruction method, problem-based learning or Socrates-style conversation method. In order to maximize learning with such different methods, intentional contents are used. It should be well understood that teacher-centered educational approach, if continued, would produce no gain. Forth, flipped learning demands specialized teachers. Some critics say the preview videos would replace the main education after all. But it is not right. In such classes, teachers play a more important role than they do in unilateral lecturing while making more frequent communication with students by group or by person. In this educational system, teachers should maximize their time to contact students according to individual level, group level and performance level. They are required to be more than teachers who just watch what students are doing. Instead, teachers need to provide feedback appropriate for each moment of their watch of children continuously in class. Also, when sharing a video lecture, they need to make comments to generate rich interaction among the learners including those in their classes and beyond.

\subsection{Educational Effectiveness of Smart Education and Flipped Learning}

Smart education based on smart devices has many similarities with mobile learning for its use of smart devices with mobility. Junghun Leem (2011) presented the key features of 
mobile learning including the mobility of learning space, flexible access to resources, individual customization, simplicity of study details, interactivity, contextuality, etc. Susil et al., (2004) suggested unvigilance, individualized/tailored class, interactivity, instantaneity and presence while Ogata and Yano (2004) presented permanent study resource management, accessibility, instantaneity, study activity and contextuality. In flipped learning, students are instructed to watch videos produced by their teachers through their own smart devices for onthe-go watching and learning. In such a manner, they can also find data anywhere anytime while having interactions via discussion with replies or collaboration mind maps. That is, the flipped learning style includes the basic ideal of smart education.

In the late 2000s, the idea of smart education has been developed in full depth. With this, many scholars tried to identify the features or nature of smart education and define it. Heeseok Lim (2011) stated that smart education was 'an overall approach to improve learning effectiveness by changing the vertical and unilateral way of conventional teaching and learning methods into horizontal, bilateral, participatory, intellectual and interactive manner'. Inae Gang, Byeongno Lim and Jeongyeong Park (2012) defined it as 'an environment where diversified learning activities are made based on the convergence of formal and informal learning, reinforced sense of presence, external learning expansion and apps to maximize learning interaction by using smart devices and social media'. Korea's Ministry of Education and Science Technology (2011) that views smart education as a way-forward for the education, defined it as 'a 21 st century education paradigm where every student is cultivate in their talented area to become a global leader by effectively applying information technology and IT-based network resources to schools for educational system reform including curriculum, education method, evaluation, environment, etc.'. The ministry also stressed that smart education did not refer to the kind of teaching that simply used smart devices but a brand new paradigm for education reform. By integrating such diverse discussions and ideas about smart education, Junghun Leem (2012) singled out the key natures of smart education: the use of cutting-edge smart devices in learning, orientation for intellectual/adaptive/customized learning, emphasis on SNS-using collaborative learning, features of converged learning between formal and informal learning and improvement of students' way of thinking and problem solving ability beyond simple information acquiring. Such education effectiveness of smart education can be applied to the flipped learning with a view to more proactive student engagement in learning. Students will have more opportunities to participate in activities at school mostly and they can do it especially through web contents, social media, e-textbooks on a voluntary base (Issue Brief: The flipped learning, 2012). In addition, the basic nature of smart education is deeply related to that of the flipped learning in that they emphasize SNS-using collaborative learning and have features of education converging formal and informal learning methods. When watching a video lecture, students can use an educational SNS to share with all others who also watch the video beyond those their classrooms for any question or comments. They can share knowledge with colleagues in classrooms and mutually teach through discussions, increasing own voluntary participation and cooperation. Informal learning part of it is self-study at home by watching videos and formal part is to structure the informally acquired knowledge in school. In this way, the flipped learning is characterized to have the feature of converged learning.

\subsection{Effects on Self-Directed Learning Ability via Smart Learning}

This research conducted flipped learning-type classes based on smart teaching method. Students, before coming to the flipped learning-style classes, watched video lectures and in school, they received classes in various kinds of different formats by using smart devices. Especially when they watched the video lectures, they were instructed to follow mind-map 
creation by cooperating with other colleagues, immediate interaction through replies, collaborated presentation making by using documentary tools, etc., in addition to simple watching. And in school, they used smart devices to understand preliminary knowledge. Students' evaluation was built in DB to analyze their study achievement. In addition, in-class student activities were not simple offline discussions and interaction but, based on smart devices, students engaged in diverse activities such as real-time web discussion, information search, collaborative presentation, collaborative mind map, etc. Through such activities, students had more opportunities to proactively participate in their classes for student-oriented class (Sunhee Bang, 2012).

Regarding smart device-using classes, Jeongrang Kim (2014) divided the 21st century learner's capacity, in his research, into creativity and innovation ability, critical way of thinking and problem solving ability, communication ability, collaboration ability, information use ability, self-directed learning ability and flexibility. And through survey on smart research schools, he found that smart education improved the 21st century learner's capacities. Jeongrang Kim (2014) interviewed students at a smart research school, Ietaewon Elementary School and stated that students said 'Team work is developed while preparing and discussing with others for the materials. Can exchange opinions and help each other. Exchange many opinions through classting and others'. Of the class activities, meaningful activities regarding the collaboration ability were observed several times. Each group head gathered their group presentation materials and posted on an educational SNS to evaluate the group members' participation. To achieve the common purpose of developing survey questions, each group showed adjusting own opinions frequently. As such, smart educationassisted improvements were witnessed in students' collaboration ability and communication ability, information use ability and self-directed learning ability. The flipped learning-style classes, if conducted in parallel with the smart education, is expected to increase students' self-directed learning ability and collaboration ability (KERIS, 2014).

\section{Research Method and Process}

\subsection{Research Participants}

To this end, the study examined 112 students in 6th grade of an elementary school $\mathrm{P}$ in Gympo-si, Gyeonggi-do. They were organized in 3 groups - Flipped classroom based on smart-learning group, normal flipped learning group and conventional ICT-using learning group. The Flipped classroom based on smart-learning group had 27 participants in total; normal flipped learning group, 28; and conventional ICT-using learning group, 47. The participating students, in a creative experience class, followed preliminary practices of smart education activities such as continuous data search by smart devices, study by using educational apps, info search by using QR codes, communication via SNS, augmented reality-based learning, and use of global resources. Before experiment, the three groups received preliminary test to check their homogeneity in terms of self-directed learning and collaboration ability. As a result, they were found to have no statistically significant difference.

\subsection{Research Design}

The independent variables of this research are flipped learning methods (smart-based flipped learning, normal flipped learning and conventional learning) and dependent variables are self-directed learning and collaboration ability. This research experiment design model is as follows: 


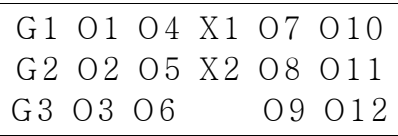

Figure 1. Experiment Design Model

\subsection{Research Tools}

This study seeks to identify any statistically significant difference in self-directed learning and collaboration ability when learners followed individual learning process and collaborative learning process in a smart education environment, compared with the conventional ICTusing class group. for this research tools, three test tools were utilized in self-directed learning and learners' capacity. For the self-directed learning ability, the self-directed learning evaluation questionnaire used in the study by Hyeon Choi and Hyeonho Jeong (2010) was employed after modifying some of its questions in line with this research purpose. The questionnaire had 30 question items in total. Test tool reliability Cronbach $\alpha$ was .959 .

Concerning the collaboration ability measurement, '21st Century Skills' developed by the KERIS (2014) was adopted herein. Its question items were developed as a performance indicator for digital/smart research schools under the sponsorship of the KEIRS, the leading responsibility of Professor Jeongrang Kim at the Gwangju National University of Education and the researcher of this present study also participated as a member. The number of questions is 27 with test tool reliability Cronbach $\alpha$ being .964 .

\section{Research Results and Interpretation}

\subsection{Analysis on Difference in Self-Directed Learning According to the Flipped Learning Method}

This study analyzed if there had been any significant difference in self-directed learning ability according to the flipped learning methods (smart-based flipped learning, normal flipped learning, and conventional learning method). As a result, the average was 4.49, 3.94 and 3.65, respectively. The one-way ANOVA results in <Table $1>$ shows statistically significant differences $(\mathrm{F}=24.264, \mathrm{p}<.05)$. As in $\langle$ Table 2$\rangle$, the post-test results of the average were found to have statistically significant differences between the flipped learning types and conventional classes.

Table 1. Anova Test of Self-Directed Learning According to Flipped Learning Methods

\begin{tabular}{|c|c|c|c|c|c|}
\hline variant & square & freedom & SS & $\mathrm{F}$ & $\mathrm{P}$ \\
\hline inter-group & 12.450 & 2 & 6.225 & \multirow{2}{*}{24.264} & \multirow{2}{*}{$.000^{* * * *}$} \\
\hline intratgroup & 25.655 & 110 & .257 & & \\
\hline total & 38.104 & 112 & & & \\
\hline
\end{tabular}

According to the results in Table 4, the smart-based flipped learning was found to have a positive effect on the self-directed learning ability. In the case of the smart-based flipped learning, as learners use their own smart pads to search relevant data and information and perform own-initiated learning procedures, it was found to work better in improving the selfdirected learning ability than the normal flipped learning and conventional ICT classes. Especially, as students use a smart pad to search data anytime anywhere instantly and interact with their peers to check and organize necessary details for learning, their self-directed 
learning ability could improve positively. The normal flipped learning showed higher level of self-directed learning ability on average than the conventional ICT-using classes but without a statistical significance.

Table 2. Results of Self-Directed Learning According to Flipped Learning Methods

\begin{tabular}{c|c|c|c}
\hline \hline & $\begin{array}{c}\text { smart-based } \\
\text { flipped leaming }\end{array}$ & $\begin{array}{c}\text { nomal flipped } \\
\text { leaming }\end{array}$ & ICT-using class \\
\hline \hline $\begin{array}{c}\text { smart-based flipped } \\
\text { leaming(M=4.49) }\end{array}$ & - & $.001^{* *}$ & $.000^{* * * *}$ \\
\hline $\begin{array}{c}\text { normal flipped } \\
\text { leaming(M=3.94) }\end{array}$ & & - & .066 \\
\hline $\begin{array}{c}\text { ICT-using } \\
\text { class(M=3.65) }\end{array}$ & & & - \\
\hline \hline
\end{tabular}

\subsection{Analysis on Difference in Collaboration Ability According to the Flipped Learning Method}

This study analyzed if there had been any significant difference in collaboration ability according to the flipped learning methods (smart-based flipped learning, normal flipped learning, and conventional learning method). As a result, the average was 4.52, 4.14 and 3.63, respectively. The one-way ANOVA results in <Table 3> shows statistically significant differences $(\mathrm{F}=17.077, \mathrm{p}<.05)$.

In collaboration ability, no statistical difference has been found between the smart-based flipped learning and normal flipped learning while statistically significant differences were found between smart-based flipped learning an ICT-using classes as well as between normal flipped learning and ICT-using classes.

\section{Table 3. Anova Test of Collaboration Ability According to Flipped Learning Methods}

\begin{tabular}{c|c|c|c|c|c}
\hline \hline variant & square & freedom & SS & $\mathrm{F}$ & $\mathrm{P}$ \\
\hline \hline inter-group & 15.107 & 2 & 7.554 & \multirow{2}{*}{17.077} & \multirow{2}{*}{$.000^{* * *}$} \\
\hline intra-group & 45.559 & 110 & .442 & & \\
\hline total & 60.667 & 112 & & & \\
$* \mathrm{p}<.01$
\end{tabular}

And as a result of the post-test results of the collaboration ability averages, as in <Table 6>, no statistical difference was found depending upon the flipped learning types but statistically significant differences were found between the flipped learning types and ICTusing classes.

As shown in the results of <Table 4>, depending upon the types of flipped learning, no statistically significant results were found in collaboration ability. This finding indicates that in the flipped learning classes, students had more opportunities to express their thoughts in speeches or writing, became able to make themselves clearer to friends while carefully 
listening to others' opinions for interaction and better understanding of the meaning behind and came to share the necessary knowledge, skills, etc. for the achievement of the team goals.

Table 4. Results of Collaboration Ability According to Flipped Learning Methods

\begin{tabular}{c|c|cc|c}
\hline \hline & $\begin{array}{c}\text { smart-based flipped } \\
\text { leaming }\end{array}$ & $\begin{array}{c}\text { normal } \\
\text { learning }\end{array}$ & flipped & ICT-using class \\
\hline \hline $\begin{array}{c}\text { smart-based flipped } \\
\text { leaming(M=4.49) }\end{array}$ & - & .117 & $.000 * * * *$ \\
$\begin{array}{c}\text { nomal flipped } \\
\text { leaming(M=3.94) }\end{array}$ & & - & $.007 * *$ \\
\hline $\begin{array}{c}\text { ICT-using } \\
\text { class(M=3.65) }\end{array}$ & & & - \\
\hline \hline \\
$\mathrm{p}<.01$
\end{tabular}

\section{Discussion and Conclusion}

This study seeks to examine the effects of the smart-based flipped learning and normal flipped learning and conventional ICT-using classes on learners' study achievement, selfdirected learning, collaboration ability, and information use ability. Based on these study findings, the following discussion can be made:

First, regardless of the types of flipped learning, it was found to have a positive effect on learners' study achievement than the conventional ICT-usinng classes. Bergmann, J. \& Sams (2013) stated, in their study, that the flipped learning could help students internalize knowledge and interact with the peers to positively affect their study achievement, the result of student participation in the process of knowledge construction. In flipped learning classes, learners cooperate actively. This, as pointed out in previous studies on collaborative learning in an e-learning environment, means that learners acquire existing knowledge and actively create new knowledge for given task performance in the process of sharing knowledge with the peers (Insuk Lee, Junghun Leem, Eunmo Seong, Seonghee Jin, 2006; Jeongsun Han, Dongsik Kim, 2009). It is likely that the flipped learning improved students' study achievement through cognitive activities. Especially given that no difference according to the types of flipped learning has been found while differences existed between the flipped learning classes and ICT classes, the flipped learning, regardless of the use of smart pads, seems to have affected learners' cognitive changes through activities such as collaborative activities, task performance, quiz, knowledge sharing, result evaluation, etc. Also while listening to online lectures, students asked and answered questions to share and create more knowledge. It seems this process has affected them as well.

Second, the smart-based flipped learning was found to increase learners' self-directed learning ability higher than the other groups. For the self-directed learning, diverse methods can be tried such as discussion and debate, individual study, investigative study, collaborative study, integrated study, topic study, project study, etc. It is not a one-way knowledge delivery by teachers but a student-designed and led class (Pildo Oh, 2007). In the flipped learning, such self-directed learning ability was improved as students did not receive unilateral teaching but followed collaborative learning, individual study, discussion and debate and knowledge sharing to learn by themselves. However, the normal flipped learning group and conventional ICT-using class did not exhibit any inter-group gap. This seems because of this 
research period of 2 month which might be not long enough to observe full growth of students/ self-directed learning ability. Also for more self-initiated study of students on their own, a certain level of further training would be necessary. But in the smart-based flipped learning group, students may have grown their own self-directed learning ability while searching for data with a smart pad and creating knowledge. Especially during their SNS use, they interact with other students or outside experts and elevated their study motivation to resolve the given task, increasing opportunities to put into practice. As such activities and experiences accumulate, students increasingly resolve their learning process and methods for themselves to cultivate their self-directed learning ability. In the smart education, in particular, it has been found that the self-directed learning ability upgrade is a key variable closely related to study achievement in a computer-assisted learning environment, hypertext environment and e-learning environment (Jeongjun Lim, Hyangnyeog Lee, 2003; Chulil Lim, 2002; Yang, 1991).

Third, the flipped learning activities were found to increase students' collaboration ability. No difference in collaboration ability was found according to the types of flipped learning activities whereas differences were found between smart-based flipped learning and conventional ICT-using class as well as between normal flipped learning and conventional ICT-using class. This cannot be said it's thanks to the smart education but it's the effect of the flipped learning. It is of course, true that the smart education does help increase opportunities of students' opinion expression or online collaboration activities but in the flipped learning, student collaboration increases during activities such as group-specific quiz, discussion, debate and project tasks. That is, students can find more opportunities to express own opinions in speeches or writing through peer instruction to make themselves clearer to friends while listening to others' opinions carefully to grasp the meaning inside through interaction and came able to share knowledge and skills necessary to achieve their team goals. Such a series of activities are deemed to have promoted students' collaboration ability. In the flipped learning, competitive study or individual study strategies can be applied to a certain limited extent but generally it organizes all classes collectively by the unit of small groups to perform activities regarding study themes and practices. Knowledge creation, the basis for collaborative study, is formed through the dynamic interaction between collaborative knowledge creation and individual knowledge creation. The former and the latter are deemed to be in a paralleled relationship (Kang \& Byun, 2001; Sthal. 2000)'. Through such a process, students experience the process of making and listening to a public statement of their tacit knowledge to undergo the argumentation phase and share understanding and create collaborative knowledge in order to objectify and formalize their knowledge (Heebae Kim, 2013).

\section{Acknowledgements}

This research was supported by Basic Science Research Program through the National Research Foundation of Korea(NRF) funded by the Ministry of Education, Science Technology(NRF-2014R1A1A1008524) and by a grant(12-TI-C01) from Advanced Water Management Research Program funded by Ministry of Land, Infrastructure and Transport of Korean government.

\section{References}

[1]. B. Seon Ah, "A study on the development of collaborative knowledge construction precedural model in blended learning", Graduate School of Hanyang Univ, (2011).

[2]. B. S. Hee, "A Study on Strategies of Self-directed Learning to Promote Smart Learning", The Journal of Korean Society for the study of Lifelong Education, vol. 8, no. 1, (2012), pp. 93-112. 
[3]. J. Bergmann and A. Sams, "Flip Your Classroom: Reach Every Student in Every Class Every Day", International Society for Technology in Education, (2012).

[4]. H. JungSun and K. D. Sik, "The Effects of Collaboration Supporting Types on Collaborative Knowledge Construction in CSCL Environment", The Journal of Korean Association for Information \& Media, vol. 15, no. 4, (2009), pp. 203-229.

[5]. J. Kim, K. Lim and Y. Park, "Research on the development of an hybrid instructional model using information technologies: "Flipped Classroom", International of Conference on Convergence Technology, vol. 2, no. 1, (2013).

[6]. J. Min, "The Effects of Flipped Classroom on Elementary Learner's Mathematics Academic Achievement and Attitude", Korea National University of Education, (2014).

[7]. K. Inae, B. R. Lim and J. Y. Park, "Exploring the theoretical framework and teaching \& learning strategies of Smart Learning: Using cases of university classrooms", The Journal of Korean Association For Educational Methodology, vol. 24, no. 2, (2012), pp. 283-303.

[8]. K. Inae and S. J. Sung, "An Activity Theoretical Analysis on Elementary Teachers' Practice of Constructivist Education", Journal of Learner-Centered Curriculum and Instruction, vol. 13, no. 5, (2013), pp. 353-382.

[9]. K. H. Bae, "A Study on Development and Application of Cooperative Learning Model for Interdisciplinary Approach in Curriculum Development", The Journal of Korean society for educational technology, vol. 28, no. 4, (2012), pp. 907-924.

[10].K. J. Rang, K. Sanghong, K. Suhwan, K. Youngsin, K. Bokyoung and H. Sunkwan, "Development effectiveness of validation tools of the digital textbook Smart learning", KERIS Lee Dong Yeop, (2013).

[11]. "Research on Developing Instructional Design Models for Flipped Learning", The Journal of Korean Society of Disital Policy \& Management, vol. 11, no. 12, (2014), pp. 83-92.

[12].L. Insook, L. Junghoon, S. Eunmo and J. Sunghee, "A Study on the Development of Collaborative Learning Model and Behavioral Elements in e-Learning Environment", The Journal of Korean association of computer education, vol. 9, no. 2, (2006), pp. 27-36.

[13].L. J. Hoon and K. S. Hong, "Effects of individual learning and collaborative learning on academic achievement, self-directed learning skills and social efficacy in smart learning", The Journal of Korean Association for Information \& Media, vol. 19, no. 1, (2013), pp. 1-24.

[14].M. H. Lee, "Computer Education Curriculum and Instru ction : Effects of Reciprocal Peer Tutoring on Academic Achievement and Satisfaction: Focused on Application Practices in Computer Operating System Lab Education", The Journal of Korean association of computer education, vol. 16, no. 3, (2013), pp. 61-70.

[15].Olmscheid and Carey, "The Efectivenes of Per Tutoring in the Elementary Grades", EDEL 695 CSU Long Beach, (1999).

[16].R. E. Hee, K. J. Bok and L. J. Sook, "Comparison of Cognitive Conflict on Peer Instruction by Middle School Science Gifted Students and Non-Gifted Students -Focusing on the level of difficulty in question”, Journal of Gifted/Talented Education, vol. 22, no. 1, (2012), pp. 117-139.

[17].S. I. Park, S. E. Lee and J. E. Song, "Major Factors Influencing Effective On/offline Learning on the Blended Learning in Higher Education", The Journal of Korean Society of Yeolin Education, vol. 15, no. 1, (2007), pp. $17-45$.

[18].S. Mitra and R. Dangwal, "Limits to self-organising systems of learning the Kalikuppam experiment", vol. 41, Issue 5, (2010), pp. 672-688.

[19].Vygotsky, "Mind in society: The development of higher psychological processes", by OREST on MAY 3, $2010 \cdot$ LEAVE A COMMENT, (1978).

[20].L. S. Vygotsky, "Mind in society: The development of higher psychological processes", (M. Cole, V. JohnSteiner, S. Scribner, \& E. Souberman, Eds.). Cambridge, Massachusetts: Harvard University Press, (1978).

[21].Y. G. Bae, "Practice of Inquiry Oriented Learning Activities in the Flipped Classroom for Multivariable Calculus", The Journal of Korean Society of Mathematical education, vol. 2, (2013), pp. 623-624.

\section{Authors}

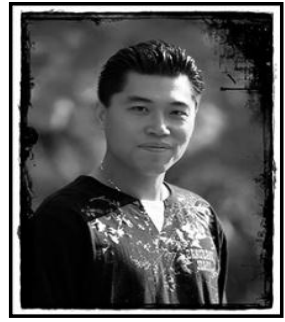

Sang-Hong Kim, he received the B.S., and M.S. degree in Computer Education from Gyeongin National University of Education, Incheon, Korea, in 2000 and 2007. He is currently a Ph.D. Candidate of Incheon University, Korea. His current interests include Educational technology, computing education and Flipped classroom. 


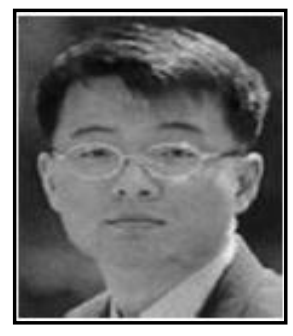

Nam-Hun Park, he received the B.S., M.S. and Ph.D. degree in Computer Science from Yonsei University, Seoul, Korea, in 2000, 2002 and 2007. He was a post-Ph.D. at the Department of Computer Science, Worcester Polytech Institute, Worcester, MA. He is currently a professor of Department of Computer Science at Anyang University, Korea. His current interests include mining data streams.

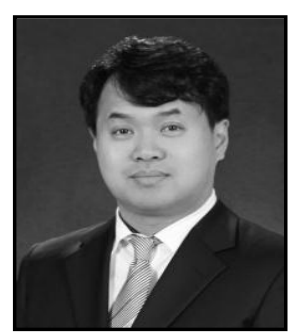

Kil-Hong Joo, he received the M.S. and Ph.D. degree in Computer Science from Yonsei University, Seoul, Korea, in 2000 and 2004. He is currently a professor of Department of Computer Education at Gyeongin National University of Education, Korea. His current interests include mining data streams, smart learning and Flipped classroom. 
International Journal of Control and Automation Vol. 7, No. 12 (2014) 